\title{
APPLICATION OF PASSIVE HARMONIC FILTERS TO MITIGATE SOURCE SIDE CURRENT HARMONICS IN AN AC - DC - DC SYSTEM
}

\author{
H. Prasad ${ }^{1}$,M. Chilambarasan ${ }^{2}$,T.D.sudhakar3 \\ ${ }^{1}$ Student, M.E Power Systems Engineering, ${ }^{2}$ Assistant Professor, Electrical and Electronics Engineering, ${ }^{3}$ Associate \\ Professor, Power Systems Engineering, St. Joseph's College of Engineering, Chennai, Tamilnadu, India.
}

\begin{abstract}
A combination of rectifier and DC - DC chopper is useful in feeding DC loads where the DC input to the loads needs to be stepped up or down. Both rectifier and chopper are based on power electronic switches which inject harmonics in the system. This harmonics is an undesirable effect which should be mitigated effectively. For this, passive harmonic filters are used. Passive harmonic filters are a simple and economical option for harmonic mitigation. Thus they find widespread application in various power systems. This paper deals with the analysis of harmonic distortion caused in a typical AC system feeding a DC motor through a rectifier and boost chopper setup. The analysis is done before and after the incorporation of passive harmonic filters on the AC side in order to study the effect of the same in the mitigation of source side harmonics.
\end{abstract}

Key Words: - Total Harmonic Distortion - THD, boost chopper, harmonics, tuned filters, resonance

\section{INTRODUCTION}

Power electronic circuits have become the need of the hour and find widespread applications due to their cost, less bulkiness, space requirement, faster control possibility etc... But their inherent problem is harmonics which is to be looked into with serious concern when considering the power quality of the system. Harmonics cause a serious impact on the quality of power by distortions, undesirable losses etc... Further they cause the mal - operation of equipments because of the disturbance from ideal conditions. Total Harmonic Distortion is the index to calculate the impact of harmonics and the level of distortion they cause in a waveform. The formula for calculating THD is given by equation 1 .

$$
T H D=\frac{\sum_{i=2}^{n} I_{i}}{I_{1}}
$$

Where $I_{i}$ denotes the harmonic orders and $I_{l}$ denotes the fundamental component. If this has to be mitigated then the conventional method is the use of passive harmonic filters [7]. Though a traditional method, passive filters are preferred even today because of their simplicity in operation, ease of implementation and economics. Passive filters are implemented in various electrical systems involving power electronic circuits to mitigate the problem of harmonics. Passive filters work on the concept of tuned RLC circuits undergoing electrical resonance at their tuned frequencies. Based on the number on tuning frequencies a filter is associated with, there are various types of passive harmonic filters in practice namely single tuned harmonic filters, double tuned harmonic filters and high pass harmonic filters or damped filters. These filters reduce harmonic components corresponding to single, two or more than two orders respectively. The choice or tradeoff between implementing filters in a system depends on the system requirements and the nature of harmonics associated with a system. They consist of simple LC elements which are readily available and thus their implementation is easier and reliable. Kuldeep Kumar Saqub sakil et.al discussed the power quality issue of harmonics and the necessity to mitigate them. They discussed in their paper the application of passive shunt filters to harmonic mitigation in a system with non linear loads along with considerations for design of filters [1]. A paper presented by Zubair Ahmed Memon et. al discussed the filter design mainly aimed to reduce current harmonics produced by non-linear loads in industries using various types of passive harmonic filters. It was observed from the simulation results that after installation of filters, current harmonics are reduced and power factor of the system is improved [3][4]. But one demerit of passive filter is they are based on lumped LC components that are tuned to a single frequency and obviously particular order of harmonics thus there is a need of large number of tuned filters in order to eliminate a larger portion of harmonics.

\subsection{Boost Converter}

There are various types of DC - DC converters namely buck, boost, buck - boost and cuk converters available today. A boost converter is preferred type of DC - DC converter in Switched mode power supplies because of their ability to step up the voltage without stacking large number of battery cells when storage space is a constraint. Boost converters are used in modern devices like LCD flashlights. Boost converters can step up small DC voltage to as many as ten times. This evades the usage of bulky transformers for step up operation. Depleted batteries cannot supply voltage 
dependent loads since their low voltage makes them un usable. Boost converters work on the mechanism of Joule thief i.e. to utilize the energy stored in depleted batteries by using the remaining energy stored in such batteries to provide the voltage for the loads. In this paper a boost converter topology to step up the input voltage by ten times is employed. This is being fed to a motor load. A schematic diagram of a boost converter is given below.

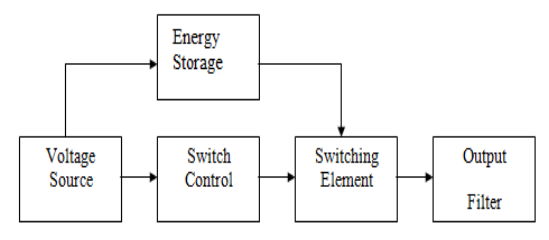

Fig1:Boost Converter

\subsection{Passive Harmonic Filters.}

Passive harmonic filters work on the principle of electrical resonance in tuned circuits which is useful in mitigating harmonic orders corresponding to a particular frequency. The concept is that at resonant frequency the tuned RLC circuit considered to be the passive filter provides a least resistance path for the harmonic current to flow out of the system that feeds the loads. Thus it reduces harmonics in the system. Apart from this passive filters can also be used to counter various power quality issues such as power factor correction also [5]. The expression for resonant frequency, number of harmonic orders, frequency vs impedance characteristics etc are given in table 1 .

Table 1 Resonant frequency of various passive filters

\begin{tabular}{|c|c|c|}
\hline $\begin{array}{c}\text { FILTER } \\
\text { TYPE }\end{array}$ & $\begin{array}{c}\text { NO OF } \\
\text { RESONANT } \\
\text { FREQUENCY }\end{array}$ & $\begin{array}{c}\text { RESONANT } \\
\text { FREQUENCY } \\
(\text { Rad/s })\end{array}$ \\
\hline $\begin{array}{c}\text { SINGLE } \\
\text { TUNED }\end{array}$ & 1 & $\omega_{n}=1 / \sqrt{ }(\mathrm{LC})$ \\
\hline $\begin{array}{c}\text { DOUBLE } \\
\text { TUNED }\end{array}$ & 2 & $\begin{array}{c}\omega_{1}=1 / \sqrt{ }\left(\mathrm{L}_{1} \mathrm{C}_{1}\right) \\
\text { and } \\
\omega_{2}=1 / \sqrt{ }\left(\mathrm{L}_{2} \mathrm{C}_{2}\right)\end{array}$ \\
\hline $\begin{array}{c}\text { HIGH } \\
\text { PASS }\end{array}$ & HIGHER & $\mathrm{F} \mathrm{o}=1 / 2 \Pi \mathrm{IRC})$ \\
\hline
\end{tabular}

The impedance offered by the filters is minimum and purely influenced only by the resistive nature of the circuit at resonance conditions. Thus maximum current corresponding to the harmonic order is filtered out from the path that feeds the loads. Here a system with rectifier and boost chopper [6] feeding a DC motor load is taken for analysis which is described below.

\subsection{Test System}

The system considered for harmonic analysis here consists of a single phase $50 \mathrm{HZ}$ AC source which feeds a DC motor load through a diode bridge rectifier and DC boost chopper setup. The rectifier consists of a diode bridge which performs uncontrolled rectification and the DC chopper is of boost type which gives an output of nearly twice the input. This setup feeds a Permanent magnet DC motor load. This rectifier and chopper topology consists of power electronic switches [6] which inject harmonics on the AC source side. This has to be mitigated by using passive harmonic filters. The schematic of the system is given in figure 2

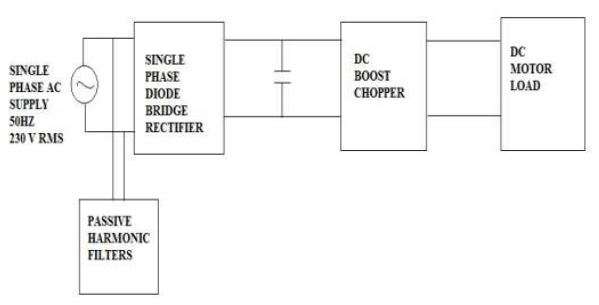

Fig2:Schematic of the System with Passive harmonic filters

The various system parameters with loads and chopper specifications are given in the following table 2.

Table 2 Test system parameters.

\begin{tabular}{|c|c|}
\hline PARAMETERS & VALUES \\
\hline Voltage & $230 \mathrm{v} \mathrm{RMS}$ \\
\hline Frequency & $50 \mathrm{~Hz}$ \\
\hline DC link capacitor & $6000 \mathrm{e}-6 \mathrm{~F}$ \\
\hline DC side inductor & $10 \mathrm{e}-3$ \\
\hline Motor load & $\begin{array}{c}\text { Permanent } \\
\text { magnet DC } \\
\text { motor }\end{array}$ \\
\hline $\begin{array}{c}\text { Sample time } \\
\text { Boost Chopper Duty } \\
\text { Cycle }\end{array}$ & $50 \% \mathrm{~s}$ \\
\hline $\begin{array}{c}\text { Boost chopper } \\
\text { Inductor }\end{array}$ & $1 \mathrm{e}-3 \mathrm{H}$ \\
\hline $\begin{array}{c}\text { Boost chopper } \\
\text { Capacitor }\end{array}$ & $1 \mathrm{e}-6 \mathrm{~F}$ \\
\hline
\end{tabular}

This system is analyzed without and with passive harmonic filters using Total Harmonic Distortion as an index. There are three different types of passive filters incorporated into the system namely a single tuned filter tuned to $7^{\text {th }}$ harmonic, a double tuned filter tuned to $3^{\text {rd }}$ and $5^{\text {th }}$ harmonic and a high pass filter to filter out harmonics above $3^{\text {rd }}$ order. The filter specifications for each type of filter are given in table 3 .

Table 3 Passive harmonic filter LC values

\begin{tabular}{|c|c|}
\hline FILTER TYPE & VALUES \\
\hline $\begin{array}{c}\text { Double tuned filter } 3^{\text {rd }} \& 5^{\text {th }} \\
\text { Harmonics }\end{array}$ & $\begin{array}{c}\mathrm{L}=5 \mathrm{mH}, \mathrm{C}=225 \mathrm{e}-6 \mathrm{~F} \\
\text { and } 81.057 \mathrm{~F}\end{array}$ \\
\hline High pass filter & $\begin{array}{l}\mathrm{R}=100 \text { ohms. } \\
\mathrm{C}=31.58 \mathrm{e}-6 \mathrm{~F}\end{array}$ \\
\hline $\begin{array}{l}\text { Single tuned filter }\left(7^{\text {th }}\right. \\
\text { harmonics) }\end{array}$ & $\begin{array}{c}\mathrm{L}=5 \mathrm{mH}, \mathrm{C}=41.356 \mathrm{e}- \\
6 \mathrm{~F}\end{array}$ \\
\hline
\end{tabular}




\section{SIMULATION AND RESULTS}

The MATLAB simulation diagram for the described system is shown in figure 3. It consists of Ac system feeding a DC motor load through a converter and chopper setup. This system is analyzed for harmonics with and without filters. A single tuned filter, double tuned filter and finally a high pass filter is also added to the source side. The results of the simulation carried out are tabulated in table 4.

Table 4 Simulation results

\begin{tabular}{|c|c|c|}
\hline $\begin{array}{c}\text { HARMONIC } \\
\text { ORDERS WITH } \\
\text { FREQUENCIES } \\
\text { IN HZ }\end{array}$ & $\begin{array}{c}\text { DISTORTION } \\
\text { WITHOUT } \\
\text { FILTERS } \\
\text { IN \% }\end{array}$ & $\begin{array}{c}\text { DISTORTION } \\
\text { WITH } \\
\text { FILTERS } \\
\text { IN \% }\end{array}$ \\
\hline $\begin{array}{c}\text { FUNDAMENTAL } \\
\text { (RMS) (50) }\end{array}$ & 14.6 & 22.1 \\
\hline $3^{\text {RD }}$ ORDER (150) & 30.51 & 20.13 \\
\hline $5^{\text {TH }}$ ORDER (250) & 10.13 & 6.68 \\
\hline $7^{\text {TH }}$ ORDER (350) & 7.47 & 4.93 \\
\hline $9^{\text {th }}$ ORDER (450) & 7.10 & 4.69 \\
\hline $11^{\text {th }}$ ORDER (550) & 6.45 & 4.26 \\
\hline $13^{\text {th }}$ ORDER (650) & 5.66 & 3.73 \\
\hline THD in \% & 37.34 & 24.63 \\
\hline
\end{tabular}

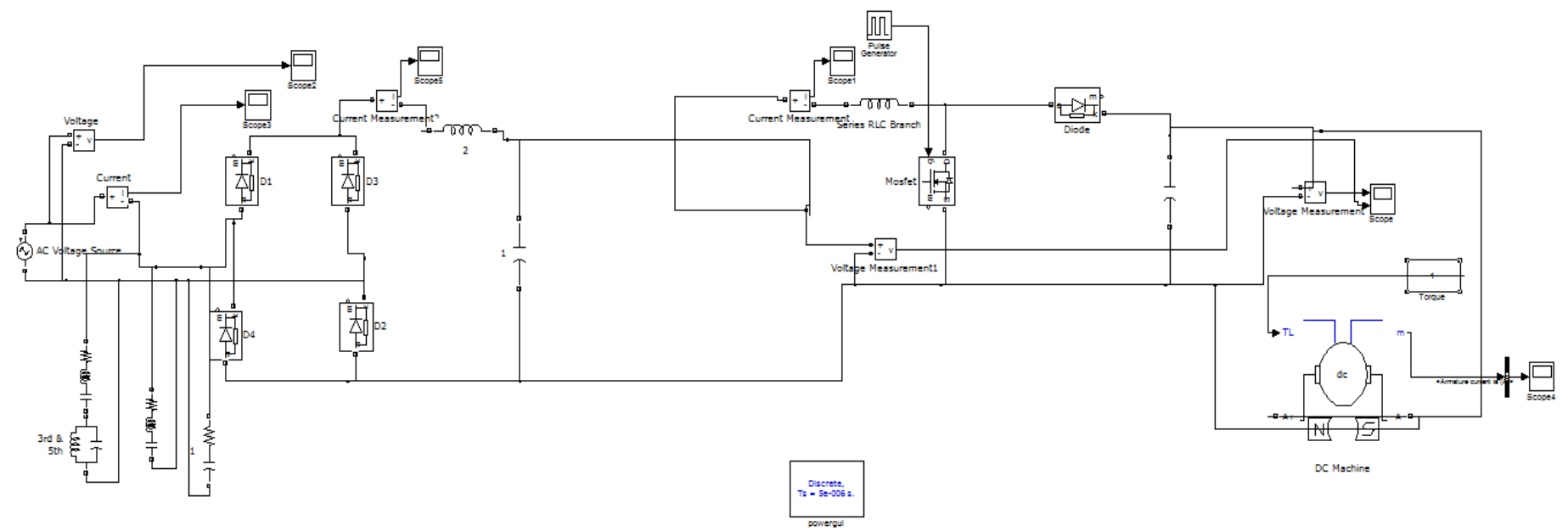

Figure 3 Simulation Using MATLAB/SIMULINK

It can be seen from the results that by incorporating passive filters the THD of the system is reduced along with individual harmonic orders.

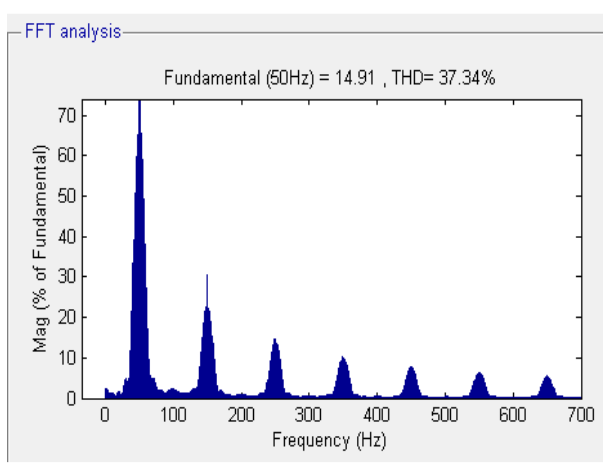

Fig4: FFT analyses without filters.

The FFT analysis window is given in figures 4 and 5 which show the percentage of harmonic currents in the spectrum before and after the filters are incorporated. This gives an idea of how individual harmonic components are mitigated with the implementation of passive harmonic filters.

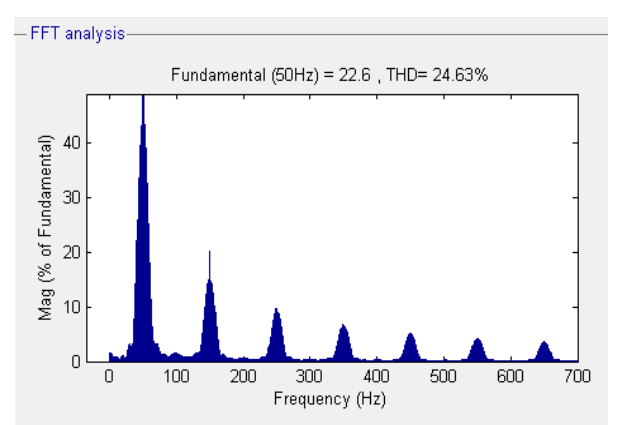

Fig5 :FFT analyses with harmonic filters

Further the quality of waveform of source current waveform which gives a visual representation of power quality improvement is also provided. 


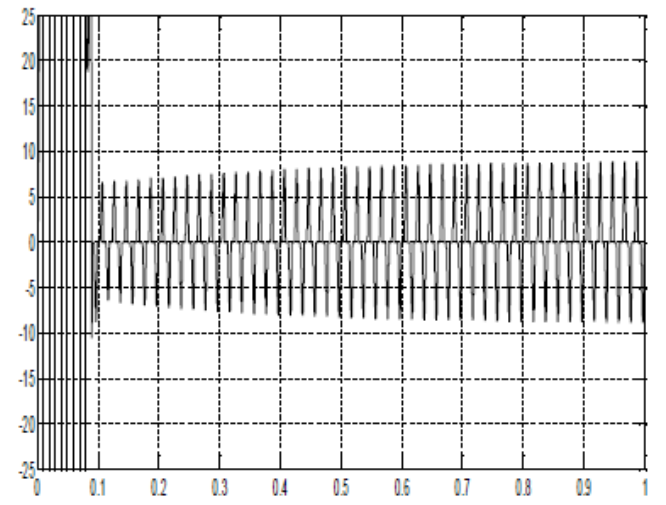

Fig 6 Source Current waveform without filters.

Figure 6 shows the distorted source current waveform before the filters are implemented. Figure 7 gives an idea of how the incorporation of filters reduces the distortion and improves the quality of current waveform.

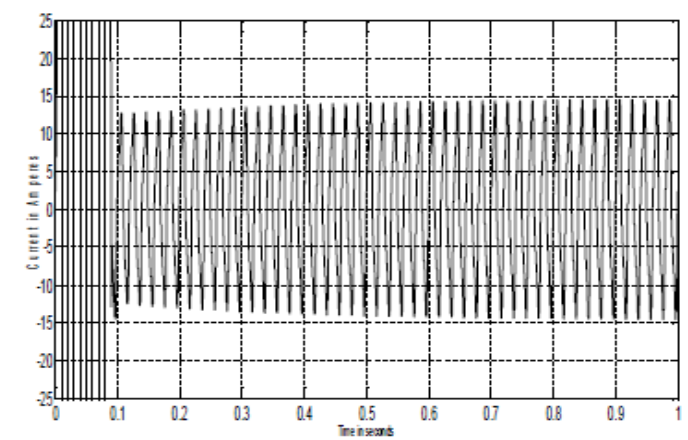

Fig 7:Source Current waveform with filters.

From the results of harmonic analysis of this system, the following are to be inferred.

\section{CONCLUSION}

Thus passive harmonic filters are an effective, easy and economical option to counter the issue of harmonics arising in small and large scale power systems or networks involving non linear loads. However passive filters suffer from the following shortcomings.

- More number of filters are required for mitigating more harmonic orders.

- This might increase the initial capital cost.

- They are characterized by sharp resonant operating points which might sometimes cause damage to the apparatus.

- Flexibility in control cannot be achieved using passive filters but on the contrary power systems are dynamic in nature and hence there is a need for flexible and automated control.

But nevertheless passive filters are always looked upon as a viable choice from economical point of view. They are also found to be effective when the system is affected by specific order harmonics to a great extent. Active harmonic filters can also be used along with passive filters as hybrid filters to compensate the shortcomings of passive harmonic filters.

\section{REFERENCES}

[1]Kuldeep Kumar Srivastava, Saquib Shakil et.al, "Harmonics \& Its Mitigation Technique by Passive Shunt Filter" International Journal of Soft Computing and Engineering (IJSCE) ISSN: 2231-2307, Volume-3, Issue-2, May 2013.

[2]Yu Lin Juan, Hsin Yin Yang et. al. "An Isolated dual input converter for Grid - PV Hybrid Power Systems". JOURNAL OF COMPUTERS, VOL. 8, NO. 6, JUNE 2013. [3]Zubair Ahmed Memon, Mohammad Aslam Uquaili, And Mukhtiar Ali Unar, "Harmonics Mitigation of Industrial Power System using Passive Filters", Mehran University Research Journal of Engineering and Technology, Volume 31, No. 2, April, 2012, pp. 355-360.

[4]Mansoor Ahmed Soomro, Muhammad Aslam Uqaili, and ZubairAahmed Memon "A novel method for the current harmonic elimination of industrial power system using single tuned shunt passive filter" Mehran University Research Journal of Engineering \& Technology, Volume 31, No. 1, January, 2012 [ISSN 0254-7821]

[5]Salvador Acevedo, Armando R. Llamas, Jesus A. Baez Jorge A. de los Reyes, "Filters for Power Factor Correction in the Presence of Non-Linear Loads" Department of Electrical Engineering Instituto Tecnológico y de Estudios Superiores de Monterrey (Monterrey Tech) Monterrey, MEXICO 64849.

[6]Muhammad H. Rashid, "POWER ELECTRONICS CIRCUITS, DEVICES AND APPLICATIONS THIRD EDITION, Pearson, New Jersey, USA"

Akagi. H," Modern active filters and traditional passive filters", Bulletin of the Polish Academy of Sciences, Technical Sciences 54(3), 255-269, 